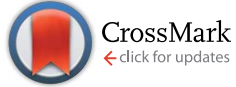

Cite this: RSC Adv., 2016, 6, 30330

DOI: $10.1039 / c 6 r a 90026 g$

www.rsc.org/advances

\section{Correction: European Viscum album: a potent phytotherapeutic agent with multifarious phytochemicals, pharmacological properties and clinical evidence}

\author{
Brahma N. Singh, ${ }^{a}$ Chaitrali Saha, ${ }^{\text {bc }}$ Danijel Galun, ${ }^{\text {de }}$ Dalip K. Upreti, ${ }^{f}$ \\ Jagadeesh Bayry ${ }^{\star b c g h}$ and Srini V. Kaveri ${ }^{\star b c g h}$
}

Correction for 'European Viscum album: a potent phytotherapeutic agent with multifarious phytochemicals, pharmacological properties and clinical evidence' by Brahma N. Singh et al., RSC Adv., 2016, 6, 23837-23857.

In the original manuscript, the Acknowledgements section was omitted. The Acknowledgements section for this manuscript is given below.

\title{
Acknowledgements
}

This work is supported by Institut National de la Santé et de la Recherche Médicale (INSERM), Centre National de la Recherche Scientifique (CNRS), Université Pierre et Marie Curie and Université Paris Descartes, Regional Program Bio-Asie 2010 by the French Ministry of Foreign and European Affairs and Institut Hiscia, Arlesheim, Switzerland.

The Royal Society of Chemistry apologises for these errors and any consequent inconvenience to authors and readers.

\footnotetext{
${ }^{a}$ Pharmacognosy \& Ethnopharmacology Division, CSIR-National Botanical Research Institute, Lucknow-226 001, India

${ }^{b}$ Institut National de la Santé et de la Recherche Médicale, Unité 1138, Paris, F-75006, France. E-mail: srini.kaveri@crc.jussieu.fr; Fax: $+33144278194 ;$ Tel: +331442782 01 ${ }^{c}$ Centre de Recherche des Cordeliers, Equipe - Immunopathologie et immuno-intervention thérapeutique, Paris, F-75006, France

${ }^{d}$ Clinic for Digestive Surgery, Clinical Centre of Serbia, Belgrade, 11000, Serbia

${ }^{e}$ Medical School, University of Belgrade, Belgrade, 11000, Serbia

${ }^{f}$ Lichenology Division, CSIR-National Botanical Research Institute, Lucknow-226 001, India

${ }^{8}$ Sorbonne Universités, UPMC Univ Paris 06, UMR S 1138, Paris, F-75006, France

${ }^{h}$ Université Paris Descartes, Sorbonne Paris Cité, UMR S 1138, Paris, F-75006, France
} 